\title{
Dê-Me Um Mapa! A Ordem Sobre A Terra
}

\author{
Give Me A Map! The Order On Earth
}

\author{
Rosilene Beatriz Machado* \\ Universidade Federal de Santa Catarina - UFSC \\ Cláudia Regina Flores ${ }^{* *}$ \\ Universidade Federal de Santa Catarina - UFSC
}

\begin{abstract}
Resumo
Este artigo tem por objetivo apresentar uma análise de como práticas de desenho e matemática foram (re)significadas nos domínios da cartografia, analisando-as em sua historicidade. Mais especificamente, colocamonos em seu campo de emergência, a fím de buscar os rastros históricos dos conteúdos escolares da disciplina de desenho, em suas relações com a matemática. Nosso propósito, assim, é analisar um dos fios do feixe de problematizações que deu as condições de possibilidade da emergência do desenho enquanto disciplina escolar, qual seja: a ordem sobre a terra.
\end{abstract}

Palavras-chave: Matemática; História; Desenho; Cartografia

\begin{abstract}
This article aims to present an analysis of how drawing and mathematics practices were (re) signified in the areas of cartography, analyzing them in their historicity. More specifically, we are in its emergency field in order to seek the historical traces of the school contents of the discipline of drawing in its relations with mathematics. Our purpose, therefore, is to analyze one of the threads of the beam of problematizations that gave the conditions of possibility of the emergence of drawing as a school discipline, namely: order on earth.
\end{abstract}

Keywords: Mathematics. History; Drawing; Cartography

\section{Introdução}

O questionamento de como domínios de saber puderam formar-se a partir de práticas sociais tem sido o fio condutor de nossa movimentação transversal de pesquisa em história(s)

\footnotetext{
* Doutora em Educação Científica e Tecnológica (UFSC). Professora do Departamento de Metodologia de Ensino do Centro de Ciências da Educação (MEN/CED) - UFSC. Vice-Líder do Grupo de Estudos Contemporâneos e Educação Matemática (GECEM). E-mail: rosibmachado@gmail.com

** Doutora em Educação (UFSC). Professora do Departamento de Metodologia de Ensino do Centro de Ciências da Educação (MEN/CED) - UFSC. Líder do Grupo de Estudos Contemporâneos e Educação Matemática (GECEM). E-mail: claureginaflores@gmail.com
} 
(da matemática, do desenho, da ciência, da educação, da educação matemática, etc.). Com Foucault, temos buscado, em nossas investigações, analisar como práticas "podem chegar a engendrar domínios de saber que não somente fazem aparecer novos objetos, novos conceitos, novas técnicas, mas também fazem nascer formas totalmente novas de sujeitos e sujeitos de conhecimento" (FOUCAULT, 2013, p. 18). O que significa, outrossim, compreender como determinadas práticas sociais teriam adquirido o estatuto de conteúdo escolar, a partir do pressuposto (sem presunção de prova, mas apenas de alargamento de potencialidades) de que investigar práticas sociais em âmbitos não escolares pode melhor esclarecer as características da vida escolar dessas mesmas práticas ${ }^{1}$; de que práticas de disciplinarização cultural (como as escolares) só são possíveis a partir de práticas de produção cultural (MIGUEL, 2010)2.

Nesse sentido, em estudo recente, problematizamos como práticas sociais de desenhar teriam adquirido o estatuto de conteúdo escolar. Situamo-nos, para tanto, em seu campo de emergência, perseguindo, enfim, os rastros da natureza histórica dos conteúdos escolares da disciplina de desenho ${ }^{3}$. Mais especificamente, analisamos como essas práticas, em sua historicidade, foram (re)significadas nos domínios da cartografia, dando-se a ver e dizer de maneiras distintas das que experimentavam até então; analisando o desenrolar desse emaranhado não pela procura das causas de uma súbita 'mudança', mas sim pelo estabelecimento do sistema de transformações em que ela consiste ${ }^{4}$.

Se escolhemos a cartografia, por outro lado, é porque, assim como em relação à matemática, estão nas Academias Militares e na 'arte da guerra' as 'origens ${ }^{5}$ do desenho enquanto disciplina escolar ${ }^{6}$. A partir do século XIV novas configurações de guerra influíram fortemente sobre as formas de se construir fortificações, criando a necessidade de uma mão-deobra especializada, fazendo surgir pela Europa as Aulas de Artilharia e Fortificação. Estas, por sua vez, passaram a formar um novo profissional: o engenheiro militar, cujo núcleo de seu

\footnotetext{
${ }^{1}$ Para uma maior compreensão acerca das perspectivas conceituais sob as quais nossos trabalhos em história(s) têm sido produzidos ver: Machado \& Flores (2016).

${ }^{2}$ Cumpre dizer que há casos bastante específicos e pontuais de conteúdos ou disciplinas que emergem e disciplinarizam-se no interior da própria escola, tal como é o caso, por exemplo, da 'gramática francesa' analisado por Chervel (1990).

${ }^{3}$ Importante destacar que o problema de pesquisa colocado trata do desenho enquanto disciplina escolar, ou seja, não se pretende uma história de alguma modalidade específica de desenho (tal como desenho geométrico, perspectivo, descritivo, técnico, arquitetônico, industrial, artístico, dentre tantos outros).

${ }^{4}$ As análises aqui apresentadas são oriundas do trabalho de tese intitulado: Cartografia, Saber, Poder: Da emergência do desenho como disciplina escolar. Ver: Machado (2016).

${ }^{5}$ Não no sentido de um começo absoluto, mas de um complexo campo de elaboração e validade em que se dá a constituição de um saber.

${ }^{6}$ Esta compreensão quanto à matemática é defendida, por exemplo, por autores tais como o historiador francês Bruno Belhoste e, especificamente no Brasil, por Valente (2007), que apontam uma estreita ligação entre guerra e educação matemática, no sentido de que as matemáticas escolares têm nas Academias Militares suas origens.
} 
ofício era dado por "estratégias de ataque, por meio dos aparelhos de guerra de artilharia e a defesa por meio das fortificações concebidas para resistir ao inimigo" (Ibidem, p. 41).

Daí que os tratados sobre fortificação foram multiplicados, a formação do engenheiro militar 'aclamada', e "a geometria e o desenho passaram a constituir uma forma privilegiada de transmissão de conhecimentos e de representação das coisas, além de um meio didático de reconhecido alcance prático" (SOROMENHO, 2001, p. 22). Além disso, segundo Valente (2007), ao final do século XVI e começo do século XVII ocorreu uma certa estabilidade e organização dos conteúdos dos tratados militares, de forma que as "questões eram abordadas segundo a ordem de conhecimentos úteis, partindo-se do mais abstrato: as matemáticas, depois o desenho, o manuseio de escalas, os diferentes tipos de fortificações” (p. 42). Pretendia-se, nas Academias Militares,

formar engenheiros militares, cartógrafos e matemáticos, capazes de levar a cabo o levantamento de mapas com latitudes determinadas pelos novos métodos empregados na Inglaterra e na França, e habilitar engenheiros a construir fortificações para a defesa dos domínios ultramarinos. (VALENTE, 2007, p.46)

O desenho ganhará, então, grande parte de seus conteúdos escolares dos tratados militares surgidos da 'arte da fortificação' nos séculos XVI e XVII, dado que será em especial da Academia Real Militar e da Academia dos Guarda-Marinha que virão professores militares e livros didáticos para o ensino nos preparatórios e liceus provinciais ${ }^{7}$. Com isso, ao longo do século XIX, após a independência do Brasil, o ensino de desenho foi gradativamente se deslocando ${ }^{8}$ do âmbito estrito da formação militar para a esfera pública, no bojo da criação das Escolas Normais (responsáveis por formar o professorado que atuaria na instrução primária); e dos Liceus Provinciais e do Colégio Pedro II, a partir de 1835 e 1837, respectivamente (ambos com vistas a garantir a formação de candidatos ao ensino superior). Os professores militares convocados para o ensino nessas novas instituições acabaram, assim, por difundir a escolarização técnico-militar desenvolvida nas Academias. A nova competência em construção de fortificações foi, portanto, fundamental para a criação da figura do engenheiro militar.

\footnotetext{
${ }^{7}$ Com a chegada da corte portuguesa ao país em 1808, o ensino sofreu significativas mudanças através da Academia Real dos Guarda Marinha, que veio junto com a corte, e da criação da Academia Real Militar em 1811, que substituiu a Real Academia de Artilharia, Fortificação e Desenho. "A academia destinava-se ao ensino das ciências exatas e da engenharia em geral, no sentido mais amplo da sua época, formando não só oficiais de engenharia e de artilharia, como também geógrafos e topógrafos que pudessem trabalhar em minas, caminho, portos, canais, pontes, fontes e calçadas. Para essa formação, os alunos teriam um curso completo de ciências matemáticas e aprenderiam física, química, mineralogia, metalurgia e história natural, além do aprendizado das ciências militares. Os candidatos à Academia deveriam ter idade igual ou superior a 15 anos (VALENTE, 2007, p. 93).

${ }^{8}$ Em um complexo processo, tal como analisado em Machado (2016).
} 
Ademais, essa mesma competência configurou-se, a partir daí, em elemento base dessa formação profissional instituída, estando o saber em desenho a ela inextricavelmente entrelaçado, ganhando visibilidade e importância.

Pois bem. De tudo isso, é preciso questionar sobre o que fez com que a 'necessidade de fortificar' tornasse-se premente ao longo e a partir do século XVI. Ainda que haja uma estreita ligação com uma nova 'arte da guerra' despontada nesse período, torna-se fundamental compreender qual o feixe de problematizações que deu as condições de possibilidade para a emergência de tal necessidade; e, junto a ela, para a emergência do desenho enquanto um saber a ensinar. Assim é que a busca por esse feixe de problematizações permite-nos alguma compreensão sobre o processo de disciplinarização ${ }^{9}$ de práticas de desenhar; e assim é que a cartografia configura-se-se em um (dentre tantos) rico território de análise, haja vista a forte presença da elaboração e conhecimento de mapas para as construções arquitetônicas a serem empreendidas e para as análises dos locais a serem atingidos belicamente.

Se nosso campo de pesquisa limita-se a esse domínio, portanto, utilizando-o [a cartografia] estrategicamente como 'ponto de ataque', é porque nele as ligações entre desenho e sua disciplinarização são densas e numerosas ${ }^{10}$. E porque há aí um emaranhado de interpositividades cujos limites e pontos de cruzamentos são bastante porosos; um território não de fronteiras fixadas, sob um efeito unificador, mas um potente multiplicador, que permite o trânsito por uma variedade de outros domínios. O que se apresenta a seguir é, pois, uma das problemáticas que constituem o referido feixe...

\section{A Ordem Sobre A Terra}

Primeiro, o príncipe passará a conhecer os territórios, podendo melhor conceber o modo de defendê-los; além disso, com os conhecimentos e com a prática adquirida nesses lugares, facilmente ele compreenderá a natureza de qualquer outro lugar que noutra vez seja-lhe necessário explorar, porquanto as colinas, os vales, as planícies, os rios e os pântanos (que existem, por exemplo, na Toscana) guardam uma certa semelhança com aqueles de outras latitudes, de sorte que do conhecimento da paisagem de uma região pode-se passar facilmente ao conhecimento de outras. Ao príncipe que faltar essa perícia

\footnotetext{
${ }^{9}$ Entenda-se disciplinarização no sentido de apropriação e ressignificação de práticas de desenhar que ganham o estatuto de conteúdo escolar. Em outras palavras, um processo de organização de um conjunto de enunciados "que tendem à coerência e à demonstratividade, que são recebidos, institucionalizados, transmitidos e às vezes ensinados como ciências" (FOUCAULT, 2009, p. 200).

10 Não há uma nítida separação nas fontes analisadas entre conhecimentos em desenho e matemática, compreendendo aí uma espécie de ‘desenho matematizado' ou 'geometria prática'. Assim, ainda que nas análises que seguem a ênfase recaia sobre o desenho, entenda-se que a matemática está contemplada nos termos que aqui destacamos.
} 
faltará a primeira das aptidões que deve possuir um capitão, já que é esta que o capacitaria a desemboscar o inimigo, a assaltar e a sitiar um território em posição de força (MAQUIAVEL, 1999, p. 83-84, grifos nossos).

A primeira coisa que o capitão deve ter é a descrição e o desenho de todo o território, de forma que ele conheça os lugares, o número, as distâncias, as vias, as montanhas, os rios e pântanos, e todas as suas características (MAQUIAVEL, 2008, p. 97, grifos nossos)

Território. É sobre ele que versam muitas das recomendações de Nicolau Maquiavel, notável secretário da Chancelaria da República de Florença, em O Príncipe, escrito em 1513, e em $A$ arte da Guerra, escrito entre 1519 e 1520, respectivamente. Um conceito que emerge no século XVI imbricado, de fato, em questões ligadas à 'arte da guerra'. Entretanto, se Maquiavel faz referência a essa relação não é porque dela seja seu precursor, mas sim, porque está inserido em uma determinada trama discursiva que se delineia nesse período, assim como tantos outros contemporâneos, teóricos militares, tais como Baldassare Castiglioni, Thomas Elyot e Leonard Digges, para citar apenas alguns exemplos.

O século XVI, com as grandes navegações, para além dos mapas do mundo, impôs uma outra urgência: os mapeamentos costeiros, característicos até então, não correspondiam às demandas de representação das novas descobertas de além-mar; o que estava em jogo agora era um processo de interiorização, "levantamento das potencialidades econômicas e reconhecimento dos aspectos geográficos das terras descobertas para seu efetivo controle e posse" (BUENO, 2007, p. 3). O que se vê, portanto, é a passagem de uma cultura de latitude, baseada na prática marítima, para um cultura de longitude, de expansão terrestre; a transformação de uma 'política expansionista' para uma 'política imperialista' (CORTESÃO \& TEIXEIRA DA MOTA, 1960: IV, 90). O que remeteu a um efetivo conhecimento e domínio das novas terras, seja através de levantamentos topográficos e corográficos ${ }^{11}$, seja através da construção de complexos sistemas de defesa militar.

Essas transformações, por sua vez, estão ligadas ao surgimento de uma nova forma de governo: à constituição e consolidação dos Estados Modernos. Forma de governo que, distintamente daquela praticada no sistema feudal, buscava estruturar-se através de uma

\footnotetext{
${ }^{11}$ A citação que segue (mantida sua ortografia original) é esclarecedora quanta à distinção entre mapas (ou cartas) topográficos, corográficos e geográficos: "Chamamos Cartas Topograficas as cartas particulares, que representão sobre hum plano huma pequena parte da terra, como por exemplo Lisboa, e seu termo, ou quando muito huma Provincia, como a Estremadura; e nestas Cartas particulares, alèm das Cidades, Villas, Aldeas, Castellos, \&c. se representão os montes, os valles, os outeiros, os Rios, Ribeiras, e lagos, os prados, os matos, as charnecas, e terras lavradas, planas, ou montanhosas; chamamos Cartas Chorograficas aquellas, que representão sobre hum plano huma parte consideravel da terra, como hum reyno, por exemplo o de Portugal, e cartas grandes as que representão huã das partes da terra, como Europa, ou Africa, \&c.; Carta Geral he aquella, que representa toda a superficie da terra em hum plano, por cuja razão se chama Planispherio, ou Mappa Mundi” (FORTES, 1722, p. 191-193).
} 
'sociedade nacional', ou seja, que basicamente estabelecia-se pela formação de um estado com idioma comum, fronteiras políticas definidas por limites territoriais, relações de poder regidas pelo conceito de soberania do rei (e não mais de suserania entre senhor feudal e vassalo) e a formação de um exército permanente.

Nesse contexto, "mapas desempenharam um importante papel na demarcação de fronteiras, na gestão de uso da terra, e na preparação para o engajamento militar" (KAGAN \& SCHMIDT, 2007, p. 662, tradução minha). Tanto que data desse período a criação de inúmeros estabelecimentos responsáveis pela produção cartográfica das monarquias, geralmente comandados por uma classe privilegiada de 'geógrafos reais'. Tais estabelecimentos produziam mapas que, além de recolher informações geográficas, desempenhavam um importante papel propagandístico, com o propósito de elevar a imagem de seu príncipe. Mais que isso, os cartógrafos empenharam-se não só no traçado de reinos existentes, mas também no delineamento de projetos de expansão futura.

Isso posto, destaque-se, em especial, a emergência do conceito de soberania territorial: um estado que se estabelece como uma unidade geopolítica, precisamente definida e limitada. Há, pois, um deslocamento fundamental que começa a ser operado com a criação dos estados modernos: a ideia de soberania não se dá mais como um exercício de poder sobre pessoas, tal como nos tempos medievais, mas sim, como exercício de poder sobre um lugar, o que, gradativamente, foi materializando a noção de territorialidade (Ibidem, p. 662). Daí que já no início do século XV questões de disputa de fronteiras passaram a ser resolvidas através de mapas, bem como, mapas tornaram-se importantes instrumentos e símbolos de poder, convertendo-se em peças de decoração de castelos a fim de evidenciar os domínios e conquistas do rei.

Por outro lado, importante ressaltar, com Kagan \& Schmidt (2007), que essa ‘conscientização do território' correu em paralelo a necessidades territoriais. Necessidades que, ainda que distintas em toda a Europa, estiveram relacionadas, de uma forma ou de outra, à problemática de defesa, convergindo para um elemento comum: mapas. Nos países baixos, por exemplo, foi a necessidade de defesa contra inundações decorrentes da baixa altitude que levou à necessidade de mapeamento de informações de distritos de águas locais. $\mathrm{Na}$ Itália, a necessidade de defesa contra invasões externas é que levou as cidades-estado a mapear seus territórios. Já países como Portugal e Espanha viram na premência em proteger seus domínios ultramarinos o impulso para o mapeamento de suas novas possessões. Logo, a guerra:

primeiramente na Itália e depois no resto da Europa, contribuiu significativamente para o aumento da consciência territorial. Ela também 
gerou uma classe de indivíduos, logo chamados agrimensores e engenheiros, que desenvolveu as habilidades matemáticas e gráficas necessárias para traçar os requisitos de defesa de uma cidade sob a forma de planos de terra ou mapas. Segue-se que alguns dos primeiros planos de terra da Europa - um sinal claro de consciência territorial - veio do norte da Itália. Um dos primeiros exemplos é o mapa de Milão, produzido para os Sforzas por volta de 1430; outro é o da cidade de Po Valley de Imola, atribuído a Leonardo da Vinci e concluída por volta de 1484 como parte da estratégia de fortificação da cidade. Assim como os planos contemporâneos de diques e terras de baixa altitude na Holanda, estes textos foram documentos de trabalho, executados para fins práticos. No entanto, eles contribuíram ao mesmo tempo para o conceito de soberania tal como veio a ser entendido em anos posteriores: controle oficial sobre o espaço em vez de pessoas (KAGAN \& SCHMIDT, 2007, p. 664, tradução nossa).

Múltiplos conflitos, ameaças militares e ofensivas militares - tanto nas terras continentais, quanto nas terras de além-mar - fizeram com que a necessidade de mapas fosse mais intensamente sentida durante o Renascimento. Não que não houvesse algum tipo de mapeamento de terra durante a Idade Média, mas somente a partir de Charles VIII, rei da França entre 1483-1498, é que se tem o primeiro registro de encomenda de uma mapa por um monarca europeu para fins de planejamento estratégico, por exemplo. Além do que, a 'descoberta do novo mundo' - um forte estímulo à produção cartográfica - só veio ocorrer no período pósmedieval. Disso, as cidades foram um grande foco do interesse geográfico, uma vez que haviam se tornado capitais da vida política, cultural e econômica na Europa, além de peças-chave no sistema de defesa militar.

Está inventado, doravante, a ideia de território. E foram os mapas os instrumentos de tal invenção na medida em que domesticaram, controlaram, apoderaram-se da natureza através de linhas que demarcam regiões contínuas e limitadas sobre esta natureza que se apresenta de maneira diametralmente oposta, isenta de continuidade e limites. Isso porque,

Território e espaço não são noções equivalentes. O território com contornos e limites precisos é uma construção histórica, produto da ação humana. Categoria aparentemente universal, falsamente natural, o território não tem nada de espontâneo. Para além das fronteiras naturais, a fronteira política é sempre uma linha abstrata e convencionada por alguns. Tal como os animais se apropriam da natureza definindo territórios, os homens "dilatam as suas conquistas", apropriam-se do espaço, percorrendo-o, conhecendo-o, nomeando-o e mapeando-o (BUENO, 2004, p. 229).

Mapas, portanto, não representam fielmente uma realidade, ao contrário, a constroem; são, na verdade, uma representação discursiva do poder, simbolizando - através de linhas posses e demarcações arbitrárias e imaginárias. Os mapas reproduzem os imperativos territoriais de um sistema político; são, enfim, verdadeiros dispositivos de visibilidade e controle que criam e dividem o espaço sobre o papel através de linhas silenciosas que favorecem 
a ideia de um espaço social - e até mesmo natural - vazio. Dessa forma é que o Tratado de Tordesilhas pôde dividir o mundo 'não-cristão' entre Portugueses e Espanhóis através de uma linha orientada no sentido norte-sul. E assim é que os personagens de Shakespeare, em Henrique $I V$, puderam repartir seus domínios sem mesmo reportarem-se até eles:

GLENDOWER - Eis o mapa. Ora vede: partiremos nossos domínios ao sabor de nossa tríplice convenção?

MORTIMER - Já o arcediago dividiu tudo em partes muito iguais: a Inglaterra, do Trento e do Severne por leste e sul até este ponto, é minha; tudo o que fica a oeste do Severne, Gales e as terras férteis deste espaço, para Owen Glendower; tudo o mais que sobra para o norte do Trento, caro primo, vos coube por quinhão. Já se acham prontos nossos contratos tripartidos, falta selálos alternadamente, coisa que poderá ser feita ainda esta noite.

(...)

HOTSPUR - Vejo que a minha parte, aqui de Burton para o norte, é menor que as outras duas. Notai como este rio vem serpeando, e corta do melhor de minhas terras este enorme pedaço em meia-lua. Vou fazer neste ponto uma barragem; em novo leito o claro e alegre Trento correrá suavemente e sem tropeços. Não mais continuará dando essas voltas para roubar-me terras tão valiosas.

GLENDOWER - Não dará mais? Bem vedes que é preciso.

MORTIMER - Notai, contudo, como ele aqui prossegue e me desfalca com igual desvantagem deste lado, mutilando no oposto continente tanto quanto vos tira naquele outro.

WORCESTER - Com bem pouca despesa o cortaríamos aqui, lucrando ao norte esta saliência: desta arte correrá sem mais obstáculos (SHAKESPEARE, Henrique IV, 1.3.1).

Segundo Bueno (2011), a necessidade de consolidar o controle das terras descobertas e redefinir o sistema de defesa dos territórios continentais, demandou um novo tipo de profissional, menos cosmógrafo, não apenas fortificador ou arquiteto, mas também agrimensor, geógrafo, topógrafo e cartógrafo. "Penetrar nas terras do novo mundo, mapeá-las, produzir seu próprio território e o das conquistas e restabelecer um sistema de defesa eficiente no reino implicava novos procedimentos, técnicas, instrumentos e agentes" (Ibidem, p. 181). Entrava em cena um novo personagem: o engenheiro militar. Foram eles que materializaram a presença do rei nas suas conquistas através dos mapas que produziam e das fortalezas, vias e cidades construídas. "Não há dúvida de que tais profissionais foram os verdadeiros braços direitos do rei no ultramar. Toda obra de porte contou com a sua presença, desde que os houvesse (Ibidem, p. 137). Com isso,

Da mesma forma que os canhões e os navios de guerra, os mapas foram as armas do imperialismo. Na medida em que os mapas serviram para promover a política colonial e onde os territórios foram reivindicados no papel antes de ser efetivamente ocupados, os mapas anteciparam o império. Os geômetras marchavam ao lado dos soldados, elaborando primeiro os mapas para as missões de reconhecimento, depois com informações gerais, antes de fazê-los instrumentos de pacificação, civilização e de exploração dessas colônias. Mas 
isto vai muito além da demarcação de fronteiras para submeter política e militarmente as populações. Os mapas prestam-se a legitimar a realidade da conquista e do império. Eles contribuem para criar mitos que ajudam a manter o status-quo territorial (HARLEY, 2009, p. 3).

É uma 'ordem sobre a terra' que se instaura a partir de então. O mundo dominado, controlado, calculado, meticulosamente desenhado através de um poderoso sistema de latitudes e longitudes que lhe conferiram certa homogeneidade, foi agora dividido, 'esquartejado', decomposto em unidades que precisam ser infimamente analisadas, dando a ver suas características. E tal ordenação só é possível porque sustentada por conhecimentos geométricos. É o desenho matematizado que fará dos mapas um dispositivo de disciplinamento, controle, vigilância; que possibilitará, por meio desses instrumentos, o cálculo, a medição, o planejamento do espaço.

\section{O Desenho Como Efeito E Suporte}

Coube ao engenheiro militar, então, em suas atribuições cartográficas, a realização principalmente de mapas topográficos e plantas de fortificações. Esses dois tipos de mapeamento eram indissociáveis para a perfeita execução dos projetos de defesa dos territórios em questão. Conforme Ballon \& Friedman (2007, p. 681-682), esse registro visual de um espaço mensurado só foi possível na Renascença em função de desenvolvimentos ocorridos nos círculos artísticos e arquiteturais italianos, em torno da técnica da perspectiva; e por conta de novos instrumentos e técnicas geométricas utilizados para medição dos terrenos. Atribui-se a Leon Batista Alberti, em meados do século XV, a apresentação do primeiro sistema geométrico de levantamento de terra:

A Descriptio urbis Romae e o Ludi matematici estão entre os primeiros tratados a contemplar a questão dos levantamentos topográficos e sua representação em mapas. Na verdade, Alberti sintetizou numerosas práticas antigas e contemporâneas, tais como as teorias do geógrafo grego Ptolomeu e as regras de triangulação simples de raiz euclidiana já empregadas na Idade Média, tais como o princípio da homotetia ou dos triângulos semelhantes. A novidade consistia em associá-los aos instrumentos náuticos empregados na medição das alturas dos astros para o cálculo da latitude (BUENO, 2007, p. 13).

O Descriptio urbis Romae (1432) trata do mapeamento de Roma, com vistas a um projeto de reformulação da cidade, encomendado pelo Papa Niccolò V e realizado entre 1443 e 1455. Alberti fornece uma extensa lista com vários registros de valores de orientação e distância que, juntos, estabelecem a posição de cada monumento observado. Além disso, descreve um 
método de transposição desses dados para o plano a partir de um sistema de coordenadas com escalas graduadas:

Tracei com a máxima precisão, servindo-me de meios matemáticos, o percurso e o desenho das muralhas, do rio e das vias, e além disso os lugares e a posição dos templos, das obras públicas, das portas e dos monumentos comemorativos, a delimitação das alturas, e ainda a superfície ocupada para fim de habitação na cidade de Roma, assim como são conhecidos em nossos dias. Idealizei além disso um método, por meio do qual qualquer um que seja dotado de inteligência mediana estará apto a representar graficamente as coisas supra ditas, no modo mais adequado e conveniente, sobre uma superfície grande a gosto. Fui conduzido a isto por amigos doutos, a cujas vontades reputei oportuno consentir (ALBERTI, 1432, p. 1).

As instruções são de que o mapa seja construído a partir do que Alberti chama horizonte: um círculo sob o qual estará compreendido o desenho da cidade que se quer realizar. Sua circunferência deve ser dividida em 48 partes iguais, chamadas graus, e numeradas progressivamente de 1 a 48, iniciando-se a setentrião (norte), seguindo em sentido horário. Cada um desses graus deve ser novamente dividido em quatro partes, chamadas minutos. Feito isso, deverá ser construído o raio: uma leve haste reta, de madeira ou metal, que tem uma extremidade fixada no centro do horizonte e a outra livre, girando ao longo da circunferência numerada. O raio deverá ser dividido em 50 partes iguais, também chamadas graus, numeradas progressivamente de 1 a 50 a partir do centro. Estas, por sua vez, deverão ser subdivididas em 4 partes cada, chamadas minutos. De acordo com o autor, cada grau do desenho corresponderá em proporção a um certo número de pés.

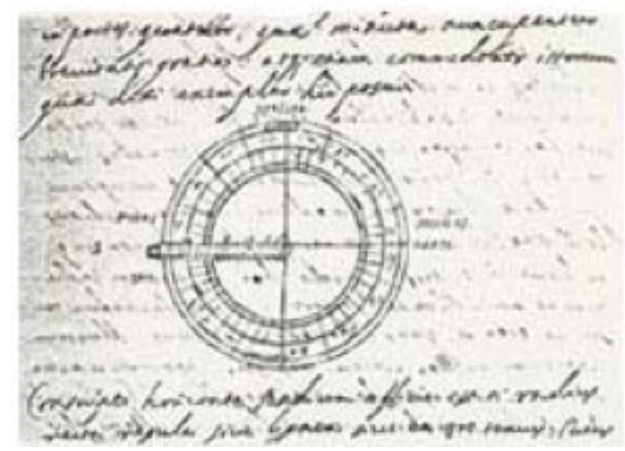

Figura 1: Modelo de horizonte e raio de Alberti. Fonte: Alberti (1432).

A partir daí, basta transferir para o papel os valores fornecidos nas tabelas, da seguinte maneira:

E note-se pois que para cada uma das tabelas se encontrarão anotadas duas colunas de números, designadas com títulos próprios. O título da primeira coluna é "Horizonte": isto indica que seus números devem ser procurados sobre o horizonte do desenho que tenhamos traçado. Na outra coluna, junto à precedente e igual a ela, é colocado o título "Raio": isto significa que os 
números escritos nesta coluna devem ser procurados no raio feito com a pequena haste.

Isto posto e estabelecido, se iniciará o desenho, partindo de uma tabela qualquer: por exemplo da primeira, intitulada "Ângulos das muralhas no Lazio". Lá, na primeira coluna, designada "Horizonte", se encontrarão escritos como primeiros números: 43 graus, 2 minutos. Este número se buscará no horizonte desenhado, e lá se colocará a extremidade móvel do raio; isto feito, se observe na tabela a linha correspondente da segunda coluna de números, intitulada "Raio". Lá se encontrarão 31 graus, 1/2 minuto: buscaremos este número no raio móvel sobre o desenho e o marcaremos traçando um ponto sobre a superfície do próprio desenho. (...) E o que se fez para os primeiros números, será prosseguido com estes e todos os outros, até levar a cabo o conjunto da tabela iniciada.

Colocados os pontos sobre a superfície desenhada, se conduzirá, de qualquer um destes a outro contíguo, uma linha reta, com exceção dos pontos em cuja tabela é colocado o título "Ápice"; a tais pontos na verdade é necessário aproximar-se e afastar-se com uma linha curva, de modo que, traçando linhas assim feitas, em correspondência a tais indicações de curvatura resulte um $\operatorname{arco}$ (ALBERTI, 1432, p. 4).

É esse o conteúdo do Descriptio urbis Romae, pequeno tratado com apenas cerca de dez páginas, grande parte delas contendo as tabelas de valores de angulação e distância dos pontos observados. Bueno (2004) afirma que o horizonte descrito por Alberti é o mesmo instrumento nomeado como polimetrum pelo cosmógrafo alemão Waldseemüller (ca.1470-1521), circumferentor ou dutch circle por Gemma Frisius e torquetum por Tartaglia (1506- 1557). "Trata-se do mais remoto ancestral do nosso moderno teodolito, assim denominado, no século XVI, por Thomas Digges” (Ibidem, p. 202). Destaque-se, ainda, que não há a construção do mapa romano pelo próprio Alberti. A figura a seguir é uma reconstrução de tal planta, a partir da descrição apresentada na obra, realizada por Alessandro Capannari em 1884:

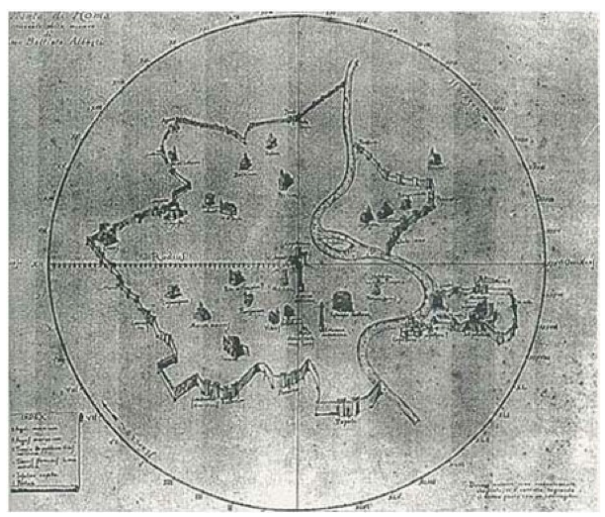

Figura 2: Construção da planta de Roma a partir da descrição albertiana por Alessandro Capannari, 1884. Fonte: Miller (1998, p. 48).

O Ludi matematici (1450-1452), por sua vez, é dividido em duas partes. Na primeira são apresentados procedimentos de medida de distâncias inacessíveis - altura de uma torre, largura de um rio, profundidade de um poço - pelas técnicas de triangulação, enquanto na 
segunda abordam-se procedimentos de medida de grandes distâncias, grandes profundidades, cargas pesadas, tempo, agrimensura e nivelamento e elaboração de mapas. O primeiro problema descrito por Alberti trata de 'Medir com a vista a altura de uma torre - Como proceder se podemos conhecer sua distância e medir diretamente uma parte dela':

Se quiser medir a altura de uma torre situada numa praça apenas olhando-a da outra extremidade, proceda da seguinte maneira. Finque uma flecha no chão, bem verticalmente, distancie-se um pouco, seis ou oito pés, e dali vise o topo da torre tomando a flecha como mira; coloque uma marca com um pouco de cera no lugar preciso em que seu olhar encontra a flecha, e chamemos $A$ essa marca de cera. Depois, do mesmo lugar em que tinha mirado o topo da torre, mire sua base e, novamente, ali onde seu olhar encontra a flecha, coloque uma marca de cera, e chamemos essa segunda marca de $B$. Finalmente, aponte o olhar para algum lugar da torre que conheça e do qual possa facilmente medir a posição até a base da torre com sua flecha, como por exemplo o pórtico de entrada, ou algum buraco, ou algo parecido situado bem embaixo. Assim como fez mirando o topo e depois a base da torre, faça enfim uma terceira marca de cera no lugar em que seu olhar encontra a flecha. Feito isso, chamemos $C$ essa terceira marca (ALBERTI, 2006, p. 8).

A figura a seguir ilustra o procedimento indicado:

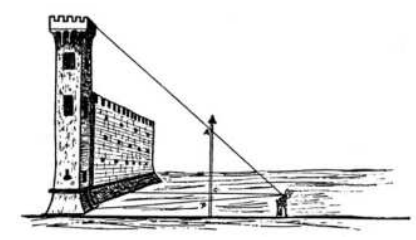

Figura 3: Técnica de medição da altura da torre. Fonte: Alberti (2006, p. 8).

Do que Alberti prossegue:

Digo que a parte da flecha que está entre a marca de cera $\mathrm{B}$ e a marca $\mathrm{C}$ cabe na parte da flecha situada entre o ponto A e o ponto B tantas vezes quanto a parte inferior da torre, já conhecida cabe na parte superior cuja altura é desconhecida. E para captar mais claramente e na prática esse procedimento, examinemos isto com um exemplo numérico (ALBERTI, 2006, p. 8).

No referido exemplo supõe-se que a torre tenha 100 pés de altura e o pórtico 10 pés. Disso, Alberti afirma que a mesma relação será encontrada sobre a flecha. Ou seja, do mesmo modo que o pórtico cabe 9 vezes na parte superior da torre e é a décima parte da torre inteira, a parte $A C$ da flecha será tal que, dividida em 9 partes, conterá 9 vezes $B C$, que é a décima parte de $B C$ considerada integralmente. Finaliza sinalizando que este procedimento nunca será falho desde que o olho seja sempre mantido no mesmo lugar para colocar as marcas. Perceba-se que este procedimento nada mais é do que uma aplicação prática das propriedades de semelhança de triângulos: 


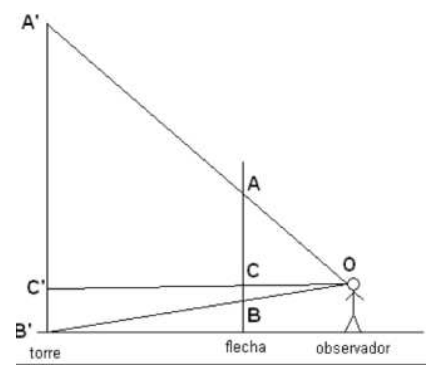

Figura 4: Esquema matemático de medição da altura da torre. Fonte: Cesana (2013, p. 103).

Como os segmentos AB e A'B' são paralelos, os ângulos Â e Â' são congruentes, assim como os ângulos B e B'. O que torna os triângulos ABO e A'B'O semelhantes, bem como os triângulos $\mathrm{BCO}$ e B'C'O. Daí que a relação apontada por $\mathrm{Alberti}$ de que $\mathrm{AB} / \mathrm{BC}=\mathrm{A} \mathrm{B}^{\prime} / \mathrm{B}^{\prime} \mathrm{C}^{\prime}$ é verdadeira. Utilizando essa mesma estratégia Alberti apresenta vários outros problemas de medição de distâncias ao longo do tratado. Essas técnicas de triangulação:

receberam ampla circulação na literatura teórica no século seguinte, começando com sua publicação por Gema Frisius em 1533. O Del modo di misvrare le distantie, de Cosimo Bartoli, em 1564, ilustra o método com a reconstrução do levantamento de Florença e seus arredores imediatos. A Mensuração indireta, chamada mensuração 'con la vista' na literatura, foi facilitada por instrumentos que tornaram a observação mais fácil e a tradução dos dados de levantamento em uma imagem gráfica mais imediata (BALLON \& FRIEDMAN 2007, p. 682, tradução nossa).

Atentemos agora para o item apresentado no Ludi matematici que particularmente nos interessa aqui: 'Elaborar o mapa de uma cidade ou região'. Alberti começa fazendo a indicação do instrumento utilizado para estabelecer a dimensão de uma região ou fazer o mapa de uma cidade, assim como fez o mapa de Roma, no Descriptio urbis Romae. Na sequência descreve como proceder:

Meça o local e os limites de uma cidade, suas ruas e seus lugares das forma seguinte. Faça um círculo sobre uma mesa grande de pelo menos um côvado e divida sua periferia com marcas em tantas partes iguais quantas quiser; quanto mais fizer, melhor ficará, contanto que sejam distintas e sem ambiguidade. Habitualmente divido o círculo em 12 partes iguais traçando diâmetros. Depois divido o limbo, isto é, o contorno em 48 partes, e chamo essas partes de graus. Depois divido cada um desses graus em quatro partes que chamo minutos. Em cada um desses graus inscrevo seus números, como está marcado na figura 24 (ALBERTI, 2006, p. 63).

O tratadista segue recomendando, então, que para elaborar o mapa deve-se colocar o instrumento em um lugar plano e elevado de onde seja possível perceber vários locais da cidade em questão. Com um fio de chumbo em mãos, o 'cartógrafo' deverá afastar-se cerca de dois 
côvados ${ }^{12}$ do instrumento visando cada um dos lugares perceptíveis a serem mapeados. Isso deve ser feito de modo que o olhar encontre ao mesmo tempo o fio de chumbo, o centro do círculo e a torre que se está mirando, anotando-se em uma folha à parte o número lido na borda do círculo na direção do que se vê.

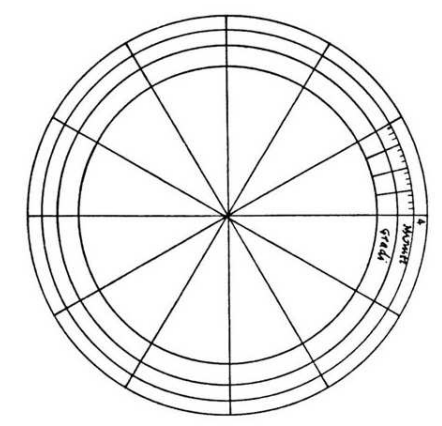

Figura 5: Instrumento descrito por Alberti. Fonte: Alberti (2006, p. 63).

Como exemplo do procedimento descrito, o autor continua:

Imagine que esteja sobre a torre do castelo com seu instrumento e que esteja visando a porta lá em cima; observe que a visada passa pela divisão 2 minutos de 20 graus; anote no papel: porta do alto 20 graus e 2 minutos. E não mexa no instrumento, é o senhor que deve se deslocar para visar os ângulos. Sua visada cairá por exemplo na inscrição 32 graus 0 minuto do instrumento; anote em sua folha: ângulo 32. E faça o mesmo para os outros pontos, sem mexer no instrumento. Feito isso, dirija-se a um segundo lugar comparável que tiver visto a partir do primeiro, e instale ali seu instrumento de tal forma que (o primeiro) esteja precisamente na reta que passa pelo número na direção do qual o senhor avistara (esse segundo lugar) sobre seu instrumento, ou seja, se um navio tivesse que partir da onde o senhor estava para onde se encontra agora, iria efetivamente sob esse mesmo vento marcado 20,2 ou 30,0 , ou outro. E de lá refaça o que fez a partir do castelo: destaque os arredores e anote tudo isso numa outra folha. Depois, dirija-se a um terceiro local, e lá proceda de novo da mesma forma, destacando tudo e anotando tudo para lembrar. (ALBERTI, 2006, p. 68).

Uma vez realizados esses registros, deve-se transpor tais valores para a superfície onde se deseja fazer o mapa. Se iniciar pelo castelo, por exemplo, deve-se escolher um ponto no papel e marcá-lo com esse nome. Sobre ele é preciso colocar um pequeno instrumento de papel de meio palmo de largura, semelhante ao grande utilizado para fazer os destaques; seu centro deve ficar sobre o ponto em questão, traçando-se a partir daí todas as retas conforme as informações anotadas. Na sequência, a instrução é de que se:

coloque igualmente um outro ponto onde lhe parecer bom sobre a reta que já traçou na superfície, reta que lhe fornece um dos outros dois lugares de onde

12 Unidade de medida baseada no comprimento do antebraço, estendendo-se da ponta do dedo médio até o cotovelo, cujo valor é em de média $45 \mathrm{~cm}$ a $50 \mathrm{~cm}$. 
havia feito as visadas, e sobre esse segundo ponto coloque também um mesmo pequeno instrumento de papel, e instale-o de maneira que a reta cujo número, em sua folha, está associado ao castelo lhe corresponda, isto é, de modo que os dois (pequenos) instrumentos sejam uma reta que, sobre cada um indique o outro lugar. Dali, trace também todas as retas segundo os números destacados em sua folha, e ali onde a reta traçada do primeiro instrumento, que indica, digamos, São Domingo, coloque um ponto e escreva em cima: São Domingo. E faça o mesmo com todos os outros lugares (ALBERTI, 2006, p. 69).

Esse mesmo procedimento, associado às técnicas de triangulação, é sugerido por Alberti para medir distâncias entre lugares. Suponha que se queira saber, por exemplo, a distância entre um determinado ponto $A$ do castelo e a torre. Basta que se registrem as informações de direção deste ponto até a torre (com auxílio do instrumento, assim como explicado anteriormente), bem como de um segundo ponto $B$ (cuja distância ao primeiro possa ser medida) até a torre. Com isto, ao transpor essas informações ao papel, tal como ao produzir um mapa, tem-se que a distância entre A e B está para a distância entre A e a torre (no mapa) da mesma forma que a distância real entre A e B está para a distância real entre A e a torre, donde encontra-se a medida procurada.

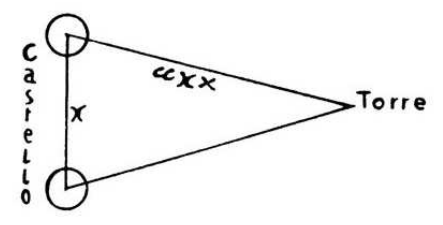

Figura 6: Ilustração do procedimento de mapeamento descrito por Alberti. Fonte: Alberti (2006, p. 72).

Essas técnicas foram apropriadas e tornadas fundamentais no ofício dos engenheiros militares. O desenho, matematizado, adaptava-se e atendia à descrição de um espaço que se queria agora calculado e, também, geometrizado. As fortalezas construídas e as cidades planejadas, nessa nova ordem sobre a terra, precisavam, portanto, ser o mais regulares possível. E isso, conforme Salomon (2002), a começar tanto por uma distribuição simetricamente organizada das ruas e das casas, quanto por uma localização precisa de corpos de guerra, casernas, depósitos, armas e munições. Assim sendo, “a geometria não fornece apenas uma imagem de como a cidade deve ser ordenada; ao contrário, é ela a sua própria imagem; é ela quem fornece um saber sobre o espaço e que produz esta simetria no seu tecido urbano. A soberania, através da engenharia militar, procede a uma geometrização do espaço a ser defendido" (Ibidem, p. 35).

O plano de toda fortaleza arquitetônica passou a ser concebido pela engenharia militar como regular ou irregular, conforme pudesse, ou não, ser inscrito em um polígono regular. O 
espaço como um todo era pensado a partir de uma figura geométrica:

A irregularidade da fortificação se define pelas figuras geométricas regulares, que se constituem como sinônimos do que é defensível e seguro; ou seja, o espaço a ser fortificado é visto como regular ou irregular porque a geometria é o saber que constitui o olhar do espaço. O tema da ordenação do espaço da cidade ou povoação, e que pretende nela estabelecer a maior regularidade possível, é proveniente desta concepção geométrica do espaço que vemos surgir com a engenharia militar e com o problema da fortificação (SALOMON, 2002, p. 37).

O principal elemento arquitetônico dessa nova forma de defesa, aperfeiçoado a partir da Renascença, foi o baluarte, caracterizando as chamadas fortificações abaluartadas, ou 'método italiano de fortificação'. Essa estrutura 'permitia o cruzamento de fogos e o flanqueamento das posições; possibilitando a defesa contra os ataques inimigos de cada um dos ângulos do elemento" (PRATA, 2011, p. 133). O baluarte, em geral, possui forma triangular, e fica posicionado nos vértices da figura poligonal que forma as muralhas cercantes à fortificação. Ele é conectado às muralhas por flancos, conferindo à estrutura como um todo uma forma pentagonal.

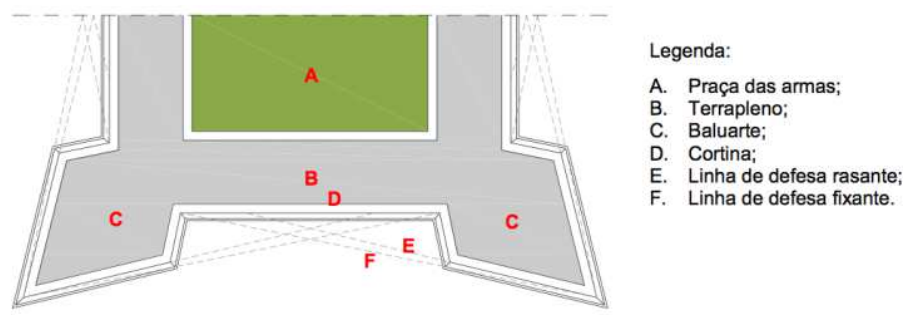

Figura 7: Plano esquemático de uma fortificação abaluartada. Fonte: Valadares (2014, p. 26).

Das faces dos baluartes provém a artilharia de ataque, enquanto os flancos são responsáveis pela artilharia de defesa. Era necessário que a disposição angular desses elementos fosse cuidadosamente calculada, conforme o método de fortificação utilizado e de acordo com a topografia do terreno, para que o fogo cruzado obtivesse a eficiência necessária em uma situação de adversidade.
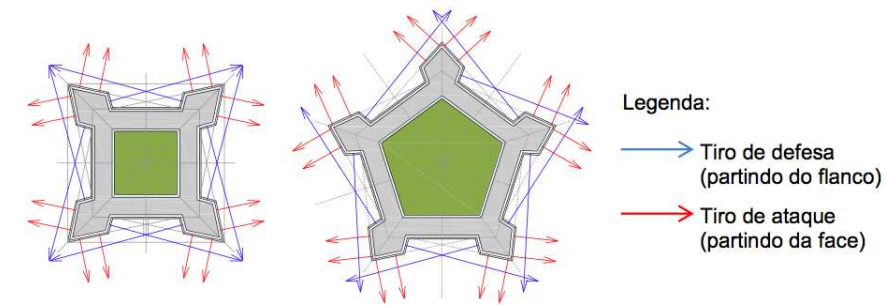

Figura 8: Representação esquemática do cruzamento de fogo entre baluartes em um forte de planta quadrangular e outro de planta pentagonal. Fonte: Valadares (2014, p. 26). 
Mas não eram apenas os contornos das fortificações que passavam a adquirir um viés geometrizado. Como destaquei, o tecido urbano do interior dessas construções também começou a ser pensado de forma a alcançar uma máxima regularidade. Isso porque, a necessidade de um ágil e prático manejo e deslocamento das pesadas peças de artilharia não se adequava às ruas estreitas e sinuosas herdadas do período medieval. Por isso, "a regularização geométrica das ruas passou a ser um artifício imprescindível para os militares, os quais incorporaram o planejamento da cidade às necessidades defensivas" (VALADARES, 2014, p. $35)$.

As cidades passaram a ser concebidas a partir de um sistema radial que dispunha as ruas de modo a convergirem para o centro geométrico da cidade. Este centro, por sua vez, também deveria assumir uma forma poligonal, de preferência a mesma do perímetro urbano, que conformava a fortificação, além de inserirem-se ali os principais edifícios públicos. Tal disposição conferia ampla visibilidade e vigilância, configurando-se em um elemento fundamental para o ordenamento e controle requeridos: "um baluarte em apuros poderia imediatamente ser visto do centro da cidade" (Ibidem, p. 40). A figura a seguir é o mapa-projeto da cidade de Rocroi, localizada na fronteira entre a França e os países baixos, construída em 1555:

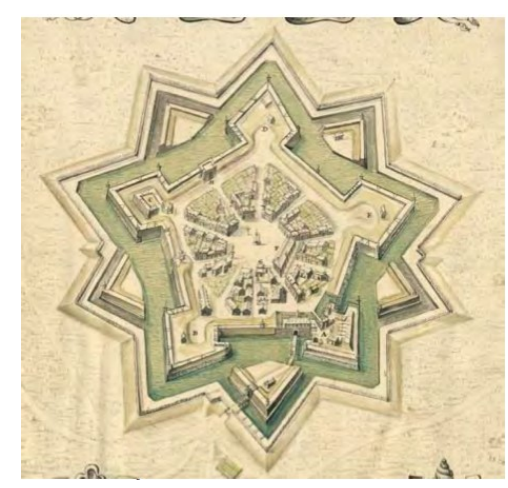

Figura 9: Projeto da cidade de Rocroi, s/a; s/d.

Fonte: Bibliotèque nationale de France. Disponível em: <gallica.bnf.fr>.

Conforme Pollak (2010), esse projeto, cujo autor é desconhecido, tem origem italiana. Perceba-se que a cidade é pensada de acordo com as premissas em voga: possui formato abaluartado pentagonal, com uma praça central igualmente conformada por um pentágono regular para onde convergem dez ruas, dispostas radialmente. Ainda que nesta malha não estejam presentes, ruas concêntricas também foram um elemento corrente dessas novas idealizações urbanas. A propósito, cabe ainda dizer que estes eram projetos de defesa, que buscavam agilidade e praticidade, mas que estavam imbricados, outrossim, em um novo ideário 
- a cidade ideal $^{13}$ - que se estabelecia na Europa, especialmente na Itália, durante o Renascimento. A cidade deveria atender a ideais de beleza que se traduziam em conceitos de ordem, simetria e harmonia, tal como preconizado pelo arquiteto romano Marcus Vitruvius Pollio, em sua obra De Architectura Libri Decem (I a.C.) e difundidos e ampliados em muitos tratados do período, em especial no De Re Aedificatória, de Alberti, escrito entre 1443 e 1452. A matemática e o desenho conferiam, ao mesmo tempo, beleza e segurança às cidades que se projetavam a partir de então.

Contudo, mesmo que a necessidade de adaptar as estruturas existentes e conceber novas obras capazes de resistir ao impacto da nova artilharia de guerra fosse uma prioridade a partir dos 1500 , é preciso ressaltar que as cidades existentes não foram totalmente remodeladas de acordo com esse novo ideário, tampouco as novas cidades construídas puderam atender plenamente a tais anseios; "a cidade ideal era só representação" (FLORES, 2003, p. 88). Na medida em que os custos operacionais e os acidentes do terreno permitissem é que os projetos de refortificação das cidades antigas e construção de novas cidades aproximavam-se em maior ou menor medida de tal idealização. Ainda assim, não há dúvida de que a busca pela superação desses obstáculos a fim de uma máxima regularidade foi uma constante no ofício do engenheiro militar.

Entrementes, esses projetos de fortificação só puderam materializar-se porque antes pensados e transcritos sobre uma folha de papel:

$\mathrm{O}$ cuidado com as informações visuais no que diz respeito com a realidade e a viabilidade da construção de uma obra; a possibilidade de calcular, medir e prever na imagem, orçamentos de matéria prima, mão de obra e tempo; a visibilidade da regularidade, da simetria e portanto da ordem do projeto, tudo isso implica na elaboração de procedimentos de representação gráfica, modos de colocar em perspectiva, principalmente aqueles que privilegiam a vista no plano e a vista total do projeto (FLORES, 2003, p. 149-150).

Tais vistas criaram ${ }^{14}$ um novo objeto pictórico: a cidade, ou a fortaleza, como um todo, internamente organizada. As projeções paralelas ganharam aí suas condições de possibilidade e meios de aplicabilidade, tornando-se uma forma privilegiada, em especial no âmbito militar, de representação de um espaço limitado. Isso porque, esse tipo de representação, diferentemente daquela resultante do uso da técnica da perspectiva linear ou central (projeção cônica), oferece

\footnotetext{
${ }^{13}$ Para uma compreensão mais alargada sobre a ideia de cidade ideal ver: Flores $(2003 ; 2007)$.

14 Tão naturalizados que somos com vistas aéreas, possibilitadas por aviões e satélites, quase não percebemos a grandiosidade da emergência desse tipo de representação em tempos em que só era possível imaginar, não efetivamente visualizar, o todo.
} 
uma visão totalitária, regular, mantendo as formas e proporções daquilo que é representado.

O sistema de projeção em perspectiva linear, uma das grandes marcas do período renascentista, não podia atender a tais necessidades de visibilidade total, já que representa o espaço a partir de um ponto de vista privilegiado, de um observador pré-fixado ${ }^{15}$. Uma vez que suas linhas projetivas convergem para um ponto único, o ponto de fuga (diametralmente oposto ao ponto de vista do observador), formando o que se chama 'pirâmide visual', os objetos representados não mantêm suas dimensões em escala real. Tanto mais estejam distantes daquele que os observa, menor serão seus tamanhos, o que muitas vezes, inclusive, faz com que elementos posicionados mais a frente acabem 'escondendo' os que estão ao fundo.

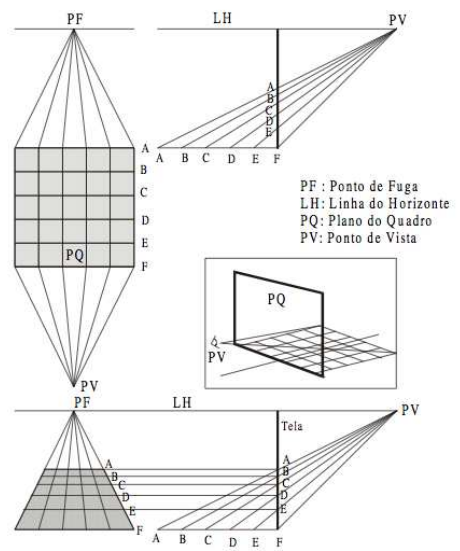

Figura 10: Esquema de projeção pela técnica da perspectiva linear. Fonte: Flores, 2003, p. 60.

A imagem a seguir é construída conforme os preceitos dessa técnica. Wagner (2012) destaca os traçados de sua composição:

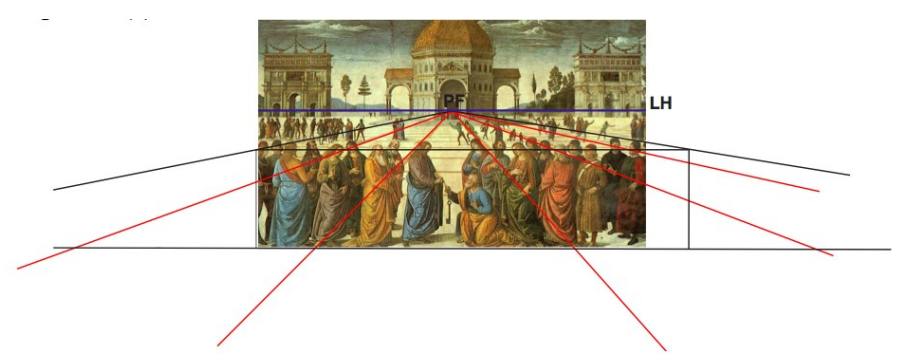

Figura 11: Perugino. Entrega das chaves a São Pedro. 1481-1482. Fonte: Wagner (2012, p. 97).

Note-se que o primeiro grupo de pessoas, localizado no primeiro plano, tem tamanho maior do que aquele mais distante. Ainda, "as linhas vermelhas, perpendiculares ao plano do quadro, acompanham as linhas do chão da praça e direcionam os olhos do observador para a

\footnotetext{
${ }^{15}$ Para uma compreensão aprofundada sobre os procedimentos requeridos pela técnica da perspectiva linear, bem como sobre sua emergência no Renascimento ver: Flores (2003; 2007).
} 
porta central do edifício. O encontro destas linhas se dá num ponto fixo, o ponto de fuga central da imagem, localizado sobre a linha do horizonte representada na imagem pela reta azul" (Ibidem, p. 97). As projeções paralelas, ao contrário, mantêm suas linhas de projeção paralelas entre si, sem convergência a um ponto de fuga. Isto faz com que a forma e as dimensões do que é representado sejam mantidas e suas medidas passíveis de serem encontradas através de escalas determinadas ${ }^{16}$.

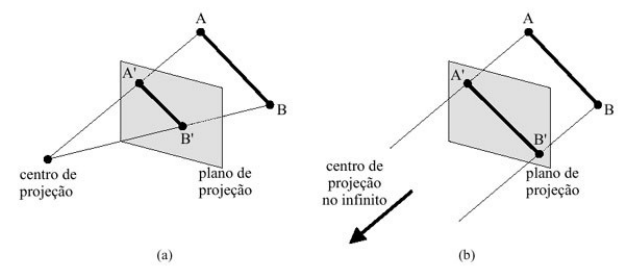

Figura 12: Esquema comparativo entre sistema de projeção perspectiva e paralela. Fonte: Disponível em: <http://professores.dcc.ufla.br/>.

Acredita-se que o Plano de Ímola (1502), de autoria de Leonardo da Vinci, seja o primeiro plano ortogonal ${ }^{17}$ de uma cidade produzido no Renascimento:

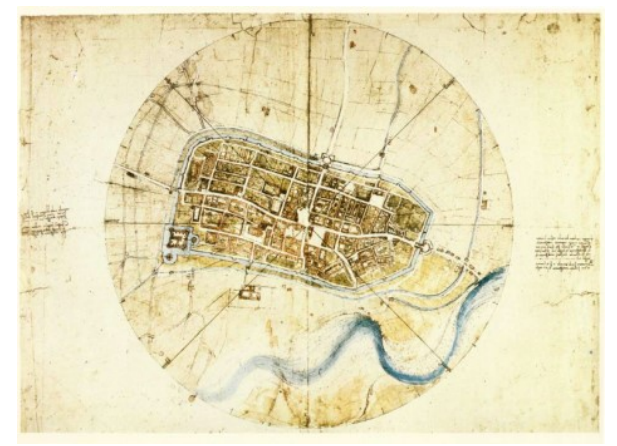

Figura 13: Leonardo da Vinci. Plano de Ímola. 1502.

Fonte: Web Gallery of Art. Disponível em: www.wga.hu

Diferentemente da imagem apresentada na Figura 11, em perspectiva linear, este plano descreve a forma global da cidade, com localização e orientação geográfica dos monumentos e construções, além da distância entre os lugares. Esse tipo de representação "não implica a presença de um observador, seja estacionário ou móvel. O plano adota um infinito número de hipotéticos pontos de vista, cada qual perpendicular ao plano da terra” (BALLON \&

\footnotetext{
16 As projeções paralelas dividem-se em axonométricas (ortogonais) e oblíquas. As projeções axonométricas incidem perpendicularmente sobre o plano de projeção e são classificadas ainda em isométricas (quando o sistema de eixos de projeção é equi-angular - 120 graus cada); dimétricas (quando apenas dois dos eixos projetam-se em ângulos iguais) e trimétricas (quando todos os ângulos dos eixos de projeção são distintos). Já as projeções paralelas oblíquas incidem obliquamente sobre o plano de projeção e são divididas em cavaleira e vôo de pássaro (ou aérea ou militar). Estas últimas serão melhor abordadas na sequência do texto.

17 Pode-se considerar que as vistas ortogonais ou planificadas são um tipo de projeção ortogonal, mas que representam apenas a face superior do objeto. Em linguagem atual, como se fosse contemplado apenas a projeção dos eixos $\mathrm{x}$ e y do triedro.
} 
FRIEDMAN, 2007, p. 689, tradução nossa). Além das vistas ortogonais, as perspectivas paralelas oblíquas, cavaleira e vôo de pássaro (ou aérea ou militar) também foram amplamente utilizadas. A perspectiva cavaleira privilegia a face frontal dos objetos, considerando-a paralela ao plano (e representada em verdadeira grandeza), com raios projetantes incidindo geralmente em 30,45 ou 60 graus.

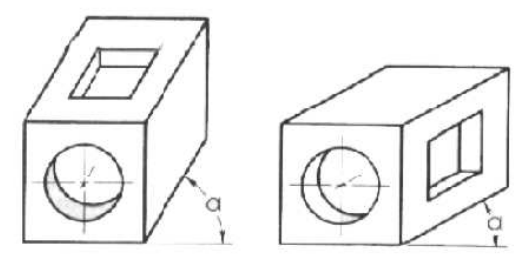

Figura 14: Perspectiva cavaleira com ângulo de projeção de 60 e 45 graus, respectivamente. Fonte: Junior (2007, p. 23).

Já a perspectiva a voo de pássaro privilegia a face superior do objeto, considerando-o paralela ao plano (e representada em verdadeira grandeza), com raios projetantes geralmente incidindo no plano em 45 graus $^{18}$.

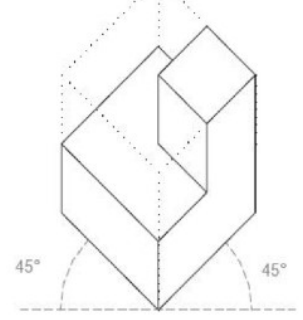

Figura 15: Perspectiva a vôo de pássaro.

Fonte: Junior (2007, p. 24).

Muitas vezes, com o intuito de conferir o máximo de visibilidade e informação possível, conjugava-se em um mesmo registro mais de uma forma de representação. "Edifícios mais importantes ou aglomerados populacionais eram restituídos em projeção ortogonal e os campos envolventes - com as construções que animavam a paisagem - em vistas cavaleiras ou a voo de pássaro" (SOROMENHO, 2001, p. 24). O mapa de Londres, produzido por Wenceslau Hollar em 1666, é representativo desse emprego múltiplo de projeções:

\footnotetext{
${ }^{18}$ Sugere-se que o nome perspectiva cavaleira, muitas vezes chamado cavalheira, tenha relação com o cavalier, um tipo de construção de altura elevada, presente em muitas fortificações militares do século XVI, de onde era possível obter uma visão ampliada do todo fortificado. A perspectiva a vôo de pássaro, por sua vez, recebe este nome por simular uma vista aérea, tal qual um pássaro. Também é conhecida por perspectiva militar por ter sido amplamente empregada na cartografia militar.
} 


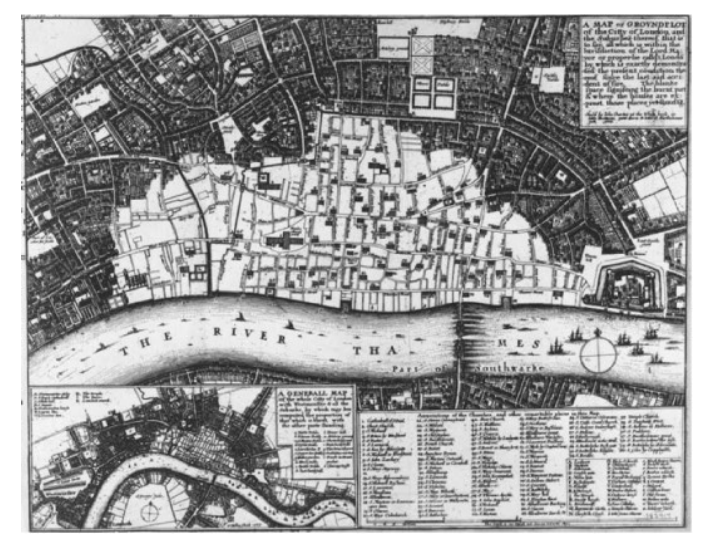

Figura 16: Londres, Wenceslau Hollar, 1666. Fonte: Ballon \& Friedman (2007, p. 695).

Este mapa, conforme Ballon \& Friedman (2007), ilustra o impacto do grande incêndio de 1666 que devastou Londres, retratada como um deserto branco. O mapa localizado no canto inferior esquerdo situa a cidade na área metropolitana, enquanto a vista maior destaca as igrejas e monumentos destruídos em branco. A combinação de vista aérea, para representar os edifícios sobreviventes, e plano, para delinear as ruas vazias, comunica à primeira vista o alcance do fogo.

Na imagem a seguir, também faz-se operar duas formas distintas de representação, ainda que não de maneira 'integrada', tal como no mapa de Hollar. É um projeto de edificação produzido por Androuet du Cerceau em 1576, em que se apresenta o plano ortogonal da construção associado a uma vista cavaleira do todo edificado:

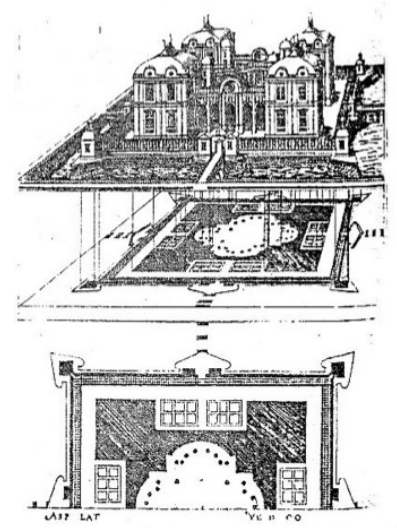

Figura 17: Androuet du Cerceau. Plano e elevação de um edifício, 1576. Fonte: Flores (2003, p. 159).

\section{Considerações Finais}

Pensamos ter evidenciado que papel assumiu o desenho, atrelado a conhecimentos matemáticos, na consolidação da ideia de território, instaurada a partir do século XVI e como a 
figura do engenheiro militar pôde emergir em meio a tudo isso. Mas é preciso, ainda, atentar para uma última questão. Conforme Flores (2003, p. 158), as perspectivas paralelas não foram usadas somente por ocasião de um regime de visibilidade total, mas também, por haverem se constituído como a possibilidade técnica de representação quando da emergência da sociedade disciplinar: uma forma de organização social que começa a se estabelecer em fins do século XVIII, baseada no controle e vigilância e que, como argumenta Foucault (1989), tem no arranjo racional do espaço e na distribuição dos indivíduos um elemento fundamental. A bem da verdade, para o autor, é o Panóptico de Bentham a figura arquitetural de tal composição espacial. Este se configura por uma construção periférica em anel, dividida em celas, cada qual atravessando toda a espessura da construção. No centro dessa estrutura fica disposta uma torre, com janelas que permitem observar todas as celas do anel, de forma que "o dispositivo panóptico organiza unidades espaciais que permitem ver sem parar e reconhecer imediatamente" (FOUCAULT, 1989, p. 166).

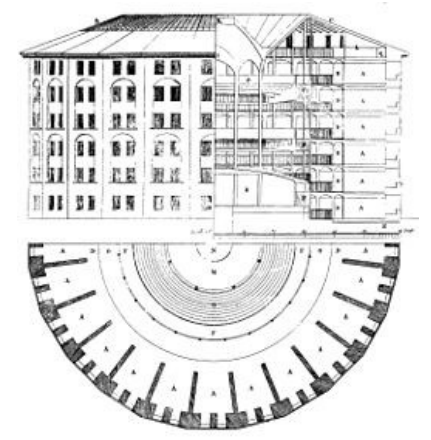

Figura 18: J. Bentham. Planta do Panóptico.

Fonte: Foucault (1999, p. 44).

Entretanto, segundo Flores (2003), essa ordem disciplinar não se dá apenas pelo panóptico, mas através de todo tipo de organização espacial que privilegie aspectos de controle:

Por exemplo, a edificação de espaços quadriculados, com fachadas retilíneas e formas geométricas na construção civil, ou a geometrização da balística, dos planos de ataque, da conduta dos soldados na arte militar, compõem-se como espaços organizados férteis para a germinação do poder disciplinar (p. 156).

Além disso, uma vez que determinado tipo de organização do espaço é veiculador de um poder disciplinar, então, as formas pelas quais o espaço é representado também estão imersas nas sutilezas da disciplina, tornando-se, igualmente, um veículo de poder:

Não há dúvidas de que as perspectivas paralelas permitem uma leitura rápida do volume, os cálculos exatos das dimensões de um objeto, uma visão do conjunto. Logo, é justamente numa estrutura social pautada na total visibilidade das coisas, na objetividade dos dados, na produção em série, no aumento da força econômica, que ela vai encontrar seu alento. Então, o modo de representar é também um modo de disciplinar. Ora, como código de leitura 
das imagens gráficas ela impõe seu funcionamento, controla a visão, disciplina o pensamento (FLORES, 2003, p.163).

Tudo isso, enfim, para ressaltar como o período renascentista, com as novas problemáticas que impôs, foi um catalisador na transformação dos mapas [e do desenho] em instrumentos de poder e, como tal, disciplinadores do espaço, produtores do território, elementos de estratégia e domínio. Os engenheiros militares, ao mesmo tempo criados por e criadores de mapas, serão os grandes difusores de sua produção e de seus efeitos nas diversas escolas militares que se instalam em inúmeros países a partir, especialmente, do século XVIII.

"Dê-me um mapa; Depois mostre-me tudo o que me resta para conquistar o mundo..." - bradava o personagem principal do escritor Cristopher Marlowe, em Tumberlaine, escrito entre 1587 e 1588. Estava posta, efetivamente, a ordem sobre a terra.

\section{Referências}

ALBERTI, Leon Battista. Descriptio Urbis Romae. Babel - Textos de Arquitetura e Urbanismo. Disponível em www.eesc.sc.usp.br/babel, 1432.

ALBERTI, Leon Battista. Matemática Lúdica. Rio de Janeiro: Jorge Zahar Editor, 2006.

BALLON, H.; FRIEDMAN, D. Portraying the City in Early Modern Europe: Measurement, Representation, and Planning. In: HARLEY, J.; WOODWARD, D. (org.). The History of Cartography, vol. III, Chicago, The Chicago University Press, 2007, p. 680-704.

BUENO, B. P. S. Decifrando mapas: sobre o conceito de "território" e suas vinculações com a cartografia. Anais do Museu Paulista. São Paulo, v.12. p. 193-234. jan./dez. 2004.

BUENO, B. P. S. Entre teoria e prática: a cartografia dos engenheiros militares em Portugal e no Brasil (séculos XVI-XVIII). Terra Brasilis - Revista de História do Pensamento Geográfico no Brasil, Rio de Janeiro, Ano VI-VII-VIII, n. 7-8-9, p.60-96, 2005-2007.

BUENO, B. P. S. Desenho e desígnio: o Brasil dos engenheiros militares (1500-1822). São Paulo: Edusp; Fapesp, 2011.

CESANA A. Cesana, Textos e contextos dos problemas de medição de alturas em livros do Renascimento. Tese de doutorado (Doutorado em Educação) - Centro de Educação, Universidade Federal do Espírito Santo, Vitória, ES, 2013, 233p.

CORTESÃO, A; MOTA, A. T. Portugaliae Monumenta Cartographica. Lisboa: Comissão Executiva das Comemorações do Quinto Centenário da Morte do Infante D. Henrique, 1960.

D'ENFERT, R. Uma nova forma de ensino de desenho na França no início do século XIX: o desenho linear. Tradução Maria Helena Câmara Bastos. História da Educação. ASPHE/UFPel, mai-ago.2007, p.31-60

FLORES, C, R. Olhar, Saber, Representar: Ensaios sobre a representação em perspectiva. Tese de 
doutorado (Doutorado em Educação) - Centro de Ciências da Educação, Universidade Federal de Santa Catarina, Florianópolis, SC, 2003. 186 p.

FLORES, C. R. Olhar, saber, representar: sobre a representação em perspectiva. São Paulo: Musa Editora: 2007.

FORTES, M. A. Tratado do modo o mais fácil e exacto de fazer as cartas geographicas. 1722.

FOUCAULT, M. F. Vigiar e Punir. Nascimento da Prisão. 7 edição. Petrópolis: Vozes, 1989.

HARLEY, B. Mapas, saber e poder. Confins [Online], 5/2009.

JUNIOR, J. T. M. A representação em perspectiva e as figuras impossiveis presentes nos trabalhos do artista gráfico Maurits Cornelis Escher. Trabalho de Conclusão de Curso - Departamento de Matemática, Universidade Federal de Santa Catarina, Florianópolis, SC, 2012, 72p.

KAGAN, R. L.; SCHMIDT, B. Maps and the Early Modern State: Official Cartography. In: HARLEY, J.; WOODWARD, D. (org.). The History of Cartography, vol. III, Chicago, The Chicago University Press, 2007, p. 661-679.

MACHADO, R. B. 2016. Cartografia, Saber, Poder: Da emergência do desenho como disciplina escolar. Tese (Doutorado em Educação Científica e Tecnológica), Universidade Federal de Santa Catarina, Florianópolis, SC, Brasil, 2016.

MACHADO, R. B.; FLORES, C. R. 2016a. Considerações Intempestivas sobre um fazer História [da Educação Matemática]. In: REVEMAT, Florianópolis (SC), v.11, Ed. Filosofia da Educação Matemática, p. 149-161.

MAQUIAVEL, N. O Príncipe. São Paulo: Martins Fontes, 1999.

MAQUIAVEL, N. A Arte da Guerra. São Paulo: Martin Claret, 2008 [1521].

MILLER, N. Mapping the City: Ptolemy's Geography in the Renaissance. In: BUISSERET, D. (org.). Envisioning the City: Six Studies in Urban Cartography. Chicago, The Chicago University Press, 1998, p. 34-74.

POLLAK, M. Cities at war in Early Modern Europe. New York: Cambridge University Press, 2010.

PRATA, M. C. R. Q. Fortificações: símbolos políticos de domínio territorial: o papel desempenhado pela Engenharia Militar na América Portuguesa. VÉRTICES, Campos dos Goytacazes/RJ, v. 13, n. 2, p. 127-145, maio/ago. 2011

SALOMON, M. O saber do Espaço: Ensaio sobre a geograficação do espaço em Santa Catarina no século XIX. Tese de Doutorado (Doutorado em História Cultural) - Centro de Filosofia e Ciências Humanas, Universidade Federal de Santa Catarina, Florianópolis, SC, 2002, 292p.

SHAKESPEARE, W. Henrique IV - peça I. Rio de Janeiro: Lacerda, 2000.

SOROMENHO, M. Descrever, registrar, instruir: práticas e usos do desenho. A ciência do desenho: a Ilustração na colecção de códigos da Biblioteca Nacional. Lisboa: Ministério da Cultura; Biblioteca Nacional, 2001.

VALADARES, P. H. C. A tratadística da arquitetura militar europeia como referência para Recife fortificado (1537-1654). Dissertação de mestrado (Mestrado em Desenvolvimento Urbano) Departamento de Arquitetura e Urbanismo, Universidade Federal de Pernambuco, Recife, PE, 2014, 
$160 \mathrm{p}$.

WAGNER, D. R. Arte, Técnica do Olhar e Educação Matemática: o caso da Perspectiva Central na Pintura Clássica. Dissertação de Mestrado. (Mestrado em Educação Científica e Tecnológica) - Centro de Ciências Físicas e Matemáticas, Universidade Federal de Santa Catarina, Florianópolis, SC, 2012, $126 \mathrm{p}$. 